\title{
Floral Biology and Pollen Viability of Some Mango (Mangifera indica L.) Cultivars
}

\author{
Sunil Kumar Mandal ${ }^{1}$, Kumari Karuna ${ }^{1 *}$, Ashwini Kumar ${ }^{1}$, \\ Abhay Mankar ${ }^{2}$ and Sanjay Sahay ${ }^{1}$ \\ ${ }^{1}$ Department of Horticulture (Fruit \& Fruit Tech.), Bihar Agricultural College, \\ Sabour, Bihar, India \\ ${ }^{2}$ Directorate of Extension Education, Bihar Agricultural University, Sabour, Bihar, India \\ *Corresponding author
}

\begin{tabular}{l} 
Ke y w o r d s \\
$\begin{array}{l}\text { Mango cultivars, } \\
\text { pollen viability, } \\
\text { anthesis, sex ratio }\end{array}$ \\
Article Info \\
$\begin{array}{l}\text { Accepted: } \\
18 \text { May } 2020 \\
\text { Available Online: } \\
\text { 10 June } 2020\end{array}$ \\
\hline
\end{tabular}

A B S T R A C T

The experiment was conducted at Department of Horticulture (Fruit and Fruit Tech.), Bihar Agricultural College under Bihar Agricultural University during the year 2017-18 to show the floral biology and pollen viability of some cultivars of mango. The results indicate that the duration of panicle initiation was highest (45 days) in Langra In respect of panicle length maximum $(38.4 \mathrm{~cm})$ was recorded in Zardalu. Highest flowering period was found in Hussan-e-ara (27 days). Highest per cent of anthesis occurred during 6.00 AM to 10.00 AM in all cultivars. Data regarding to number of flowers per panicle were maximum in Langra (1003). In respect of number of male flowers it was found significantly maximum in Langra (705). Number of hermaphrodite flowers was also maximum (298) in Langra. Sex ratio is an important parameter for determination of fruiting behaviour and ultimately yield. Highest sex ratio (2.7) was recorded in Gulabkhas and Hussan-eara. For hybridization programme pollen viability as well as pollen germination per cent is important parameters. Highest pollen viability per cent $(90.6 \%)$ was observed in Hussan-e-ara.

\section{Introduction}

Mango (Mangifera indica L.) is one of the choicest tropical fruit tree in the world belongs to family Anacardiaceae. In mango, both perfect and hermaphrodite flowers occur on the same panicle (Fraser, 1927). Anthesis starts early in the morning and completes at noon. Stigma receptivity remains for 72 hours but most receptive period is for the first 6 hours. Minimum pollen germination time is 1.5 hours (Spencer and Kennard, 1955). Initial fruit set depends upon the ratio of the number of hermaphrodite flowers to male flowers.

Proportion of hermaphrodite flowers required for optimum fruit set must not be less than 1 per cent. Flowering time and type of flower influenced the mango fruit set, production and 
its quality. Gulabkhas, Vanraj, Hussan-e-ara, Langra, Zardalu and Amrapali are categorized as early flowering mango cultivars under Indian condition. Avilan et al., (1998) studied flower diversity in twenty one mango cultivars of Venezuela and reported that flower number per panicle varies from 601 (cv. Haden) to 4,859 (cv. Irwin). Moreover, it was also reported that percentage of female flower varies from cultivars to cultivars.

Like flowering time, fruit colour is also an important parameter, which significantly influences the mango trading among consumers. So far, inheritance pattern of fruits colour has not been studied well but available research reports revealed that it has been governed by polygenes and different colour fruit was observed due to different gene combinations.

The style of the hermaphrodite flower has a small stigmatic surface grooved as a receptive surface for pollen grains (Ding and Darduri, 2013). The point at which flower buds fully open and become functional is called anthesis, which used to happen during the morning hours. Polyembryonic cultivars tend to begin anthesis during the predawn hours (Wagle, 1929; Pimentel et al., 1984) whereas, monoembryonic types tend to open during the daylight morning hours (Musahib-ud-din and Dinsa, 1946; Singh, 1954; Randhawa and Damodaran, 1961), but there are exceptions to the rule.

For example, the polyembryonic cultivars, Carabao and Piko have been reported to open at 9:00 am to 10:00 am (Pimentel et al., 1984). Anther dehiscence occurs, usually during the early morning hours (Singh, 1960), soon after anthesis and is continuous throughout the day reaching its maximum in the morning hours (Mukherjee, 1953). In Bihar, commercial mango cultivars are Langra, Zardalu and Amrapali.
These varieties remained yellowish green even after maturity. Presently, the main focus for mango breeding program was to develop regular bearing, high yielding colour cultivars for domestic as well as export markets.

\section{Materials and Methods}

The present investigation was carried out in the Department of Horticulture (Fruit and Fruit Tech.), Bihar Agricultural College, Sabour under Bihar Agricultural University, Sabour, Bhagalpur, Bihar on floral biology, pollen viability and compatibility study in six different cultivars of mango.

The Bihar Agricultural College, Sabour, Bhagalpur is situated at $25^{\circ} 15^{\prime} \mathrm{N}$ latitude and $86^{\circ} 57^{\prime} \mathrm{S}$ longitude at an altitude of $46 \mathrm{~m}$ above the mean sea level. According to table no. 1 , the monthly average temperature was the maximum in April (32.9 $\mathrm{C}$ ) and the minimum in January $\left(6{ }^{\circ} \mathrm{C}\right)$.

The present study was carried out on six mango cultivars namely, Amrapali, Zardalu, Hussan-e-ara, Langra, Gulabkhas and Vanraj available at the experimental orchard of the Department of Horticulture (Fruit and Fruit Technology), BAU, Sabour, Bhagalpur.

The selection of mango cultivars was made on the basis of their importance in mango breeding programme. Trees of these mango cultivars were fairly old (10-12 years), healthy and free from diseases and pests. The plants of these mango cultivars were maintained under uniform cultural practices.

\section{Panicle emergence and duration of panicle emergence}

Time of panicle emergence on bearing shoots was given different ratings as suggested by Rathore, 2005. 


\begin{tabular}{|c|c|c|}
\hline $\begin{array}{c}\text { Panicle } \\
\text { emergence }\end{array}$ & Period & Rating \\
\hline $\begin{array}{c}\text { Very early } \\
\text { Early }\end{array}$ & $\begin{array}{c}\text { Before } 10^{\text {th }} \text { February } \\
11^{\text {th }}-17^{\text {th }} \text { February }\end{array}$ & 2 \\
\hline Mid & $18^{\text {th }}-24^{\text {th }}$ February & 3 \\
\hline Late & $25^{\text {th }}$ February to $3^{\text {rd }}$ & 4 \\
\hline March & \\
\hline Very late & After $3^{\text {rd }}$ March & 5 \\
\hline
\end{tabular}

\section{Flowering duration}

Flowering duration was recorded in days from the date of first flower opening to the date of last flower opening in a panicle. Day to $50 \%$ bloom was calculated on the basis of number of days taken for opening of 50 per cent flowers on individual tree.

\section{Panicle length and breadth}

The inflorescence length was measured from the base to the tip of fully developed panicle (inflorescence) with the help of a measuring scale and expressed in $\mathrm{cm}$. The panicle breadth was recorded in the middle portion of the fully developed inflorescence with the help of a measuring scale and expressed in $\mathrm{cm}$.

\section{Anthesis}

Anthesis of the flowers was recorded for eight days of selected five panicles at random, all round the tree in each cultivar. These panicles were tagged with numbering and number of flowers open were recorded and removed at interval of two hours, from 6 a.m. to 4 p.m.

\section{Number of flowers per panicle}

Number of flowers per panicle is observed by selecting panicle on tree at random in each cultivar. These panicles were tagged and numbered. Flowers were counted and removed daily at the interval of 2 hours in cultivars from the opening of first flower to the last flower which was open in these panicles.

\section{Male, hermaphrodite flowers and sex ratio}

The male flowers are similar to the hermaphrodite flowers but are without the pistil, which has been aborted. Hermaphrodite flowers are small $(5-10 \mathrm{~mm})$ with four to five ovate and pubescent sepals and four to five oblong, lanceolate, thinly pubescent petals. Only one or two of the four to five stamens that arise from the inner margin of the disc are fertile.

The single ovary is born centrally on the disc with the style arising from one side. There are five large, fleshy stamens, only one or two of them being fertile; the remaining stamens are sterile stamenoides. In general, mango ovaries are green, spherical and easy to make out, its slender style pointing skyward and ending with a tiny stigmatic area where pollen grains germinate.

For counting male and hermaphrodite flowers, 10 panicles were tagged in each tree on four directions. Observations on male and hermaphrodite flowers were recorded during middle of flowering season when specific cultivar attained $>50 \%$ bloom.

Total numbers of flowers of above discussed kinds were counted in fully opened panicles with naked eyes and with the help of magnifying lens. In order to avoid error the counted flowers on panicles were removed and fresh open flowers were counted on daily basis. Sex ratio was calculated by dividing number of male with hermaphrodite flowers by using following formula. This indicates the presence of male flowers per hermaphrodite flowers.

Sex Ratio $=\frac{\text { Number of male flowers }}{\text { Number of hermaphrodite flowers }}$ 


\section{Pollen viability per cent}

Each morning fresh flowers were collected at the time of anther dehiscence, between 07:00 am and 08:00 am (Lim and Gumpil, 1984). Pollens were collected from the flowers at the beginning of anthesis. The well grown flowers were picked in the full flowering season. They were put in paper bags or polythene bags and were transferred to the laboratory. Petals and sepals were separated and anthers isolated from flower buds and immediately placed in petri dishes lined with moistened filter paper to avoid pollen desiccation for releasing pollens.

Viability test of pollen in each cultivar were carried out by two steps through acetocarmine test:

\section{Acetocarmine test}

\section{Preparation of acetocarmine solution}

It was prepared by boiling one gram of carmine in 55 cubic centimetre of distilled water and 45 cubic centimetre glacial acetic acid. It was cool, decanted and two drops of saturated aqueous solution of ferric acetate was added. After $12 \mathrm{hrs,} \mathrm{solution} \mathrm{was} \mathrm{filtered}$ and kept for further use.

\section{Pollen staining}

The pollen grains were spread on a clean glass slide and few drops of the acetocarmine solution was added and stirred well with a needle. In a few minutes the viable pollen took the stain and examined under microscope after putting the cover slip over the field, viable pollen stained and becomes deep red while non-viable pollen stained bluish to black.

To determine viability about three hundred pollen grains of each replication from four different areas were counted under a light microscope. To calculate the pollen grain viability, the following formula was used:

Pollen viability percentage $=\frac{\text { No. of stained pollen grains }}{\text { Total no of counted pollen grains }} \times 100$

\section{Results and Discussion}

Panicle emergence and duration of panicle emergence

Differences among cultivars in date of initiation of panicle emergence were observed. Early initiation (01-02-2018) of panicle emergence was observed in Gulabkhas which was nearby Zardalu (02-022018) and followed by Langra and Vanraj (05-02-2018). Late initiation (10-02-2018) of panicle emergence was observed in Amrapali which was nearby Hussan-e-ara (09-02-2018). Differences among cultivars in date of completion of panicle emergence were recorded. Early completion (14-02-2018) of panicle emergence was seen in Gulabkhas which was nearby in Langra (15-02-2018) and late (26-02-2018) in Vanraj followed by Hussan-e-ara (23-02-2018).

The analysis of variance in respect of duration of panicle emergence indicated that all cultivars were found significant difference among each other (Table 2). The maximum duration of panicle emergence (24 days) was recorded in cultivar Vanraj which was followed by Zardalu (17 days), Hussan-e ara (14 days) and Gulabkhas (13 days) whereas, minimum duration of panicle emergence ( 8 days) was recorded in Amrapali.

Muhammad et al., (2002) were studied on three commercial cultivars of mango i.e Anwar Rataul, Dashehari and Langra and found that early panicle initiation was observed in Dashehari followed by Langra and Anwar Rataul. Similar results were also 
found by Kumar and Jaiswal (2003) at Sabour, Bihar. They had showed that longest duration of panicle emergence (56 days) in Langra, earliest panicle emergence $\left(8^{\text {th }}\right.$ January) in Neelum but panicle emergence in other varieties started from $19^{\text {th }}$ January to $31^{\text {st }}$ January and continued up to $24^{\text {th }}$ March.

\section{Flowering duration}

Critical observation of data (Table 3) showed that differences among cultivars in date of initiation of flowering. Early initiation (1402-2018) of flowering was observed in Gulabkhas which was nearby in Langra (1502-2018) and followed by Amrapali (18-022018) and Zardalu (19-02-2018). Late initiation of flowering was observed in Vanraj (26-02-2018) which was nearby Hussan-e-ara (23-02-2018).

Observation on duration of flowering differed from variety to variety of mango and showed a range of 22 days in Gulabkhas to 27 days in Hussan-e-ara. But as the temperature increases during the flowering period it hastened the process of blooming of the cultivars simultaneously. This was the reason that though Hussan-e-ara took more days to bloom but was at par with three other varieties Zardalu, Vanraj. Mallik (1957) also reported the duration of flowering in mango from 25 to 35 days under Sabour conditions.

Thus, it is clear that blooming period is affected by the environment under which the plant grows. Variation in duration of flowering in different varieties might be also due to their genetic make-up. The varieties which had more days for blooming period should have wider span of time for availability of its fruit. But, it will not hold good in all cases because during the development of fruits other factor also effect the maturity of fruits such as climate and genetic constitution of the varieties.
A perusal of data revealed that differences among cultivars in date of $50 \%$ flowering were recorded. Completion of $50 \%$ flowering was done in Langra (22-02-2018) which was nearby with Gulabkhas (23-022018) followed by Zardalu and Amrapali (2502-2018) and late (04-03-2018) in Vanraj which was followed by Hussan-e-ara (02-032018).

A critical examination of data showed that differences among cultivars in date of full bloom. It was first observed in Gulabkhas (02-03-2018) which was nearby with Langra (03-03-2018) followed by Zardalu (07-032018) and (05-03-2018). Among these cultivars it was late in Vanraj (16-03-2018) which was nearby with Hussan-e-ara (15-032018).

A perusal of analysis of variance indicated that the data significantly differed among the cultivars. The maximum duration of flowering (27 days) was observed in Hussane-ara which was followed by Zardalu (25 days), Amrapali and Vanraj (24 days). The minimum duration of flowering (22 days) was recorded in Gulabkhas which was at par with Langra (23 days).

Both pure and mixed panicles were found in six cultivars. The selection of the panicles were made representative of the whole tree by selecting the panicles from the north, south, east, and west directions.

By the observation it was found that Zardalu and Hussan-e-ara have both terminal and auxillary panicles whereas rest cultivars have only terminal panicles. The percentage of particular types may vary according to the cultivar and growth flushes, "on" and "off" year, age of the tree, direction, position and types of shoots. This is also in agreement with the findings of Iqbal et al., (1995), Mazumder et al., (2011) and Kanchan et al., (2018). 


\section{Length and width of panicle}

With regard to the data (Table 4), the analysis of variance in respect of length of panicle during one year was found non-significant. It was varying ranged between Hussan-e-ara $(24.5 \mathrm{~cm})$ to Vanraj $(27.0 \mathrm{~cm})$. The width of panicle was maximum $(18.50 \mathrm{~cm})$ in cultivar Zardalu which was at par with Gulabkhas $(17.50 \mathrm{~cm})$ whereas minimum in Vanraj $(14.30 \mathrm{~cm})$ which was par with rest of the treatments. Uthaiah et al., (1988) also recorded the length of panicle ranged between $12.4 \mathrm{~cm}$ to $38.6 \mathrm{~cm}$ in different varieties of mango under coastal Karnataka conditions. Thimmappaiah and Suman (1987) also observed similar trend in different varieties of mango at Lucknow. In present study, the breadth of panicle varied between $14.3 \mathrm{~cm}$ to $18.5 \mathrm{~cm}$. These variations might be due to genetical behaviour of the variety and environment conditions of that area. This is in agreement with Dhaliwal et al., (1999) in mango.

\section{Anthesis}

The observations observed (Table 5) were subjected to statistical analysis which clearly stated that there were significant differences among the cultivars during year 2018. During early in the morning i.e from 6 am to 8 am the maximum anthesis per cent was recorded in Gulabkhas (47.27) which was at par with Vanraj (45.03) and Zardalu (43.80). Minimum anthesis per cent was recorded in Langra (36.01) which was at par with Amrapali (38.14) and Hussan-e-ara (39.56).

During morning period from 8 am to $10 \mathrm{am}$, highest anthesis per cent was recorded in Hussan-e-ara (50.42) which was followed by Amrapali (44.62), Vanraj (43.17) and Gulabkhas (42.43). Lowest anthesis per cent was recorded in Langra (35.16) which was at par with Zardalu (39.60).
At the period of 10 am to 12 noon maximum anthesis per cent was recorded in Amrapali (11.31) which was at par with Zardalu (10.68) followed by Langra (9.14) and Vanraj (7.89) whereas minimum was observed in Hussan-eara (6.08) which was at par with Gulabkhas (6.20).

At the time period of 12 am to $2 \mathrm{pm}$ maximum anthesis per cent was recorded in Zardalu (4.34) which was at par with Amrapali (4.16) and Langra (4.05) whereas minimum was observed in Hussan-e-ara (2.52) which was at par with Gulabkhas (2.57) and Vanraj (2.56).

In afternoon period i.e from $2 \mathrm{pm}$ to $4 \mathrm{pm}$, maximum anthesis per cent was recorded in Amrapali (1.77) which was followed by Gulabkhas (1.52) and Zardalu (1.53) whereas minimum was observed in Vanraj (0.70). The percentage of anthesis of staminate and perfect flowers varied at different times on open sunny days. There was no fixed rate for it. Percentage of opening of staminate and perfect flowers also varied in six cultivars on the sunny days. It was observed that in open sunny days more percentage of perfect flowers opened and in cloudy day more percentage of staminate flowers opened in six cultivars. No definite relationship between temperature and humidity with maximum opening was observed in any of the six cultivars in open sunny day and cloudy day. According to Pimentel et al., (1984) observed that polyembryonic cultivars Carabao and Piko have been reported to open at 9:00 am to 10:00 am.

\section{Number of flowers per panicle}

A perusal of analysis of variance table indicated significant difference in number of flowers per panicle produced by different cultivars of mango (Table 6). Maximum number of flowers per panicle was recorded 
in Langra i.e., (1003) followed by Amrapali (880) and Zardalu (850) whereas minimum was noted in Vanraj (782) which was at par with Hussan-e-ara (785). Temperature has a direct effect on number of flowers per panicle, the maximum number of flowers per panicle in Langra due to low temperature in February and increases temperature affect the opening of flower, opening of flower also depend on the genetic constituent of the mango tree, this finding has supported by various previous workers also. Avilan et al., (1998) was reported that flower diversity in twenty one mango cultivars of Venezuela and reported that flowers number per panicle varies from 601 (cv. Haden) to 4,859 (cv. Irwin).

\section{Number of male flowers per panicle}

A perusal of analysis of variance indicated that there was significant difference in number of male flowers per panicle among the cultivars (Table 6). Highest number of male flowers was recorded in Langra (705), followed by Gulabkhas (609) which was at par with Zardalu (600), Hussan-e-ara (562) and Amrapali (560) whereas lowest in Vanraj (480) which was at par with Amrapali (560).

The number of male flowers in a particular cultivar is due to genetic make-up which also vary from place to place due to changed environmental conditions. This is the reason that the same variety Langra produced 1,061 male flowers per panicle at Saharanpur (Singh, 1954). Yadav and Singh (1993) also reported that the number of male flowers produced in a panicle is a varietal character.

\section{Number of hermaphrodite flowers per panicle}

The observations recorded (Table 6) on number of hermaphrodite flowers per panicle were subjected to statistical analysis. The analysis of variance indicated that there was significant difference in number of hermaphrodite flowers per panicle among the cultivars. Maximum number of hermaphrodite flowers was recorded in Amrapali (320) which was at par with Vanraj (302) and Langra (298). Minimum number of hermaphrodite flowers per panicle was found in Hussan-e-ara (208) which was at par with Gulabkhas (220).

\section{Sex ratio}

With regard to the data presented (Table 6) revealed that the sex ratio of six mango cultivars was differed significantly. The lowest sex ratio was observed in Vanraj (1.5) which was followed by Amrapali (1.7), Langra (2.3) and Zardalu (2.4) whereas highest was noted under Gulabkhas and Hussan-e-ara (2.7). The change in sex-ratio in different cultivars might be due to weather conditions as well as inherent characters of individual cultivar. These findings are also in agreement with Yadav and Singh (1993).

\section{Pollen viability percentage}

A perusal of analysis of variance showed that significant differences in pollen viability percentage among six cultivars of mango. The highest pollen viability percentage was observed in Hussan-e-ara (90.6) which was at par with Amrapali (89.3) which in turn at par with Langra (82.7).

Lowest pollen viability percentage was recorded in Zardalu (77.2) which was at par with Gulabkhas (81.8) and Vanraj (81.7). Pollen viability percentage is affected by weather condition and genetic make-up of the different mango cultivars. Sharma and Singh (1972) also reported that pollen viability was higher (90) in the cultivars Dashehari, Langra, Bombay green and Chausa as observed (Table $6)$. 
Table.1 Weather condition prevailing during experiment period (December 2017 to April 2018)

\begin{tabular}{|c|c|c|c|c|c|}
\hline \multirow[t]{2}{*}{ Date } & \multicolumn{2}{|c|}{ Temperature ( C) } & \multicolumn{2}{|c|}{ Relative Humidity (\%) } & \multirow{2}{*}{$\begin{array}{c}\text { Rainfall } \\
\text { (mm) }\end{array}$} \\
\hline & Max. & Min. & 07.00 A.M. & 02.00 P.M. & \\
\hline 02 Dec. - 08 Dec. & 23.0 & 11.7 & 96.0 & 72.0 & 00.0 \\
\hline 09 Dec. - 15 Dec. & 18.7 & 8.0 & 97.0 & 75.0 & 00.0 \\
\hline 16 Dec. - 21 Dec. & 23.3 & 8.2 & 95.0 & 59.0 & 00.0 \\
\hline 23 Dec. - 31 Dec. & 23.0 & 10.0 & 96.0 & 74.0 & 00.0 \\
\hline 01 Jan. - 07 Jan. & 20.9 & 8.6 & 98.0 & 76.0 & 00.0 \\
\hline 08 Jan. - 14 Jan. & 21.3 & 8.0 & 96.0 & 61.0 & 00.0 \\
\hline 15 Jan. - 21 Jan. & 22.7 & 6.0 & 93.0 & 48.0 & 00.0 \\
\hline 22 Jan. - 28 Jan. & 25.1 & 8.2 & 91.0 & 59.0 & 12.4 \\
\hline 29 Jan. - 04 Feb. & 22.2 & 8.0 & 98.0 & 63.0 & 00.0 \\
\hline 05 Feb. - 11 Feb. & 25.8 & 7.9 & 89.0 & 51.0 & 00.0 \\
\hline 12 Feb. - 18 Feb. & 26.6 & 9.5 & 95.0 & 46.0 & 00.0 \\
\hline 19 Feb. - 25 Feb. & 28.4 & 11.5 & 86.0 & 44.0 & 00.0 \\
\hline 26 Feb. - 04 Mar. & 29.2 & 10.5 & 83.0 & 36.0 & 00.0 \\
\hline 05 Mar.-11 Mar. & 28.9 & 12.9 & 84.5 & 53.2 & 3.2 \\
\hline 12 Mar.-18 Mar. & 28.4 & 11.9 & 83 & 49.5 & 0.6 \\
\hline 19 Mar.-25 Mar. & 30.3 & 16.4 & 87.5 & 56.1 & 5.9 \\
\hline 26 Mar.-01 Apr. & 31.5 & 21.5 & 94.2 & 67.4 & 0 \\
\hline 02 Apr.-08 Apr. & 32.9 & 21.7 & 92.5 & 64.2 & 0 \\
\hline
\end{tabular}

Table.2 Initiation of panicle emergence, completion of panicle emergence and duration of panicle emergence (days) in some mango cultivars

\begin{tabular}{|c|c|c|c|}
\hline Cultivars & $\begin{array}{c}\text { Initiation of panicle } \\
\text { emergence }\end{array}$ & $\begin{array}{c}\text { Completion of panicle } \\
\text { emergence }\end{array}$ & $\begin{array}{c}\text { Duration of panicle } \\
\text { emergence (days) }\end{array}$ \\
\hline Langra & $05-02-2018$ & $15-02-2018$ & 10 \\
\hline Zardalu & $02-02-2018$ & $19-02-2018$ & 17 \\
\hline Amrapali & $10-02-2018$ & $18-02-2018$ & 8 \\
\hline Gulabkhas & $01-02-2018$ & $14-02-2018$ & 13 \\
\hline Vanraj & $05-02-2018$ & $26-02-2018$ & 24 \\
\hline Hussan-e-ara & $09-02-2018$ & $23-02-2018$ & 14 \\
\hline C.D.(p=0.05) & & & 1.23 \\
\hline
\end{tabular}

Table.3 Initiation of flowering, date of $50 \%$ flowering, date of full bloom and duration of flowering in some mango cultivars

\begin{tabular}{|c|c|c|c|c|}
\hline Cultivars & $\begin{array}{c}\text { Initiation of } \\
\text { flowering }\end{array}$ & $\begin{array}{c}\text { Date of 50\% } \\
\text { flowering }\end{array}$ & $\begin{array}{c}\text { Date of full } \\
\text { bloom }\end{array}$ & $\begin{array}{c}\text { Duration of } \\
\text { flowering (days) }\end{array}$ \\
\hline Langra & 15.02 .18 & 22.02 .18 & 03.03 .18 & 23 \\
\hline Zardalu & 19.02 .18 & 25.02 .18 & 07.03 .18 & 25 \\
\hline Amrapali & 18.02 .18 & 25.02 .18 & 05.03 .18 & 24 \\
\hline Gulabkhas & 14.02 .18 & 23.02 .18 & 02.03 .18 & 22 \\
\hline Vanraj & 26.02 .18 & 04.03 .18 & 16.03 .18 & 24 \\
\hline Hussan-e-ara- & 23.02 .18 & 02.03 .18 & 15.03 .18 & 27 \\
\hline C.D.(p=0.05) & & & & 1.36 \\
\hline
\end{tabular}


Table.4 Length and width of panicle in some mango cultivars

\begin{tabular}{|c|c|c|c|}
\hline Cultivars & Types of panicle & $\begin{array}{r}\text { Length of panicle } \\
(\mathbf{c m})\end{array}$ & $\begin{array}{c}\text { Width of panicle } \\
(\mathbf{c m})\end{array}$ \\
\hline Langra & Terminal & 25.6 & 16.00 \\
\hline Zardalu & Terminal \& Axillaries & 26.0 & 18.50 \\
\hline Amrapali & Terminal & 26.8 & 15.40 \\
\hline Gulabkhas & Terminal & 25.5 & 17.50 \\
\hline Vanraj & Terminal & 27.4 & 14.30 \\
\hline Hussan-e-ara & Terminal \& Axillaries & 24.5 & 15.20 \\
\hline C.D.(p=0.05) & & 2.81 & 1.86 \\
\hline
\end{tabular}

Table.5 Anthesis per cent of some mango cultivars

\begin{tabular}{|c|c|c|c|c|c|}
\hline Cultivars & $\mathbf{6 ~ a m - 8 a m}$ & $\mathbf{8 a m - 1 0 a m}$ & $\mathbf{1 0 a m}-12 \mathbf{a m}$ & $\mathbf{1 2 a m - 2} \mathbf{p m}$ & $\mathbf{2} \mathbf{p m}-\mathbf{4} \mathbf{p m}$ \\
\hline Langra & 36.01 & 35.16 & 9.14 & 4.05 & 1.13 \\
\hline Zardalu & 43.8 & 39.60 & 10.68 & 4.34 & 1.53 \\
\hline Amrapali & 38.14 & 44.62 & 11.31 & 4.16 & 1.77 \\
\hline Gulabkhas & 47.27 & 42.43 & 6.20 & 2.57 & 1.52 \\
\hline Vanraj & 45.03 & 43.17 & 7.89 & 2.56 & 0.72 \\
\hline Hussan-e-ara & 39.56 & 50.42 & 6.08 & 2.52 & 1.42 \\
\hline C.D.(p=0.05) & 4.2 & 4.9 & 0.8 & 0.3 & 0.14 \\
\hline
\end{tabular}

Table.6 Number of male flowers, no. of hermaphrodite flowers, sex ratio and pollen viability per cent in some mango cultivars

\begin{tabular}{|c|c|c|c|c|c|}
\hline Cultivars & $\begin{array}{c}\text { Number of } \\
\text { flowers per } \\
\text { panicle }\end{array}$ & $\begin{array}{l}\text { No. of male } \\
\text { flowers }\end{array}$ & $\begin{array}{c}\text { No. of } \\
\text { hermaphrodite } \\
\text { flowers }\end{array}$ & Sex ratio & $\begin{array}{c}\text { Pollen } \\
\text { viability per } \\
\text { cent }\end{array}$ \\
\hline Langra & 1003 & 705 & 298 & 2.3 & 82.7 \\
\hline Zardalu & 850 & 600 & 250 & 2.4 & 77.2 \\
\hline Amrapali & 880 & 560 & 320 & 1.7 & 89.3 \\
\hline Gulabkhas & 829 & 609 & 220 & 2.7 & 81.8 \\
\hline Vanraj & 782 & 480 & 302 & 1.5 & 81.7 \\
\hline Hussan-e-ara & 785 & 562 & 208 & 2.7 & 90.6 \\
\hline C.D.(p=0.05) & 1.86 & 80.35 & 33.06 & 0.09 & 6.13 \\
\hline
\end{tabular}

As discussed above in the conducted experiment, the maximum days of completion of panicle emergence was seen in cultivar Vanraj. The maximum anthesis of different mango cultivars was observed in early day hours between 06:00 am to 08:00 am. The highest number of hermaphrodite flowers and sex ratio was recorded in Amrapali. The maximum pollen viability percentage was observed in Hussan-e-ara. These data could be used in several breeding programs of mango especially for developing new cultivars with coloured traits, regular bearing characteristics, etc. and other various research purposes. 


\section{References}

Avilan L, Rodríguez M, Ruiz J (1998) El Cultivo del Mangueroen Venezuela FONAIAP Edition, Maracay, Venezuela, pp. 59-92.

Dhaliwal, L. K., Koonrt, B. S., Singh, J. and Soni, A. S. (1999). Incidence of Helicoverpa armigera (Hubner) in relation to meteorological parameters under Punjab conditions. $J$. Agrometeorol. 6 : 115-19.

Ding, P. \& Darduri, K.B.( 2013). Morphology of Chok Anan mango flower grown in Malaysia. African Journal of Agricultural Research (8): 1877-1880.

Fraser S (1927) American Fruits, Their Propagation, Cultivation, Harvesting and Distribution. Orange- Judd Publishing CInc., New York. pp.829.

Iqbal SM, Uddin, MS and Sharker MA (1995) Performance of exotic mango germplasm under Bangladesh conditions. In: Annual Report on Mango Improvement, Regional Horticultural Research Station, BARI, Nawabgonj. pp.1-9.

Kanchan Bhamini, Anjani Kumar, Jaiswal US, Md. Feza Ahmad, Ruby Rani (2018) Morphological Characterization of Mango (Mangifera indica L.) Germplasm Using DUS Testing. International Journal of Current Microbiology and Applied Sciences 7(5):2319-7706 .

Kumar N and Jaiswal US (2003) Bearing behaviour of some South and West India mangoes and its vegetative growth. Haryana Journal of Horticultural Sciences 33(1/2):9-10.

Lim ES, Gumpil JS (1984) The flowering, pollination and hybridisation of groundnuts (Arachis hypogaea L.). Pertanika 7:61-66.

Majumder DAN, Hassan L, Rahim MA, Kabir MA (2011) Studies on physio- morphology, floral biology and fruit characteristics of mango. Journal Bangladesh Agriculture University 9(2):187-199.

Mallik, P. C. (1957) Morphology and biology of the Mango flower. Indian J. Hort.

Muhammad A, Muhammad U, Muhammad JJ, Muhammad MK (2002) Comparative study of flower sex ratio in different cultivars of Mango (Mangifera indica L.). International Journal Agriculture Biology 4(2):220-221.

Mukherjee SK (1953) Origin, distribution and phylogenetic affinities of the species of Mangifera indica L. Journal Linnanus Socciety Botany 55:65-83.

Musahib-Ud-Din ,Dinssa HS (1946) The floral count and fruit set studies in some of the North Indian mango varieties. Punjab Fruit Journal 10:35-42.

Pimental RB, Coronet RE, Espino RFC (1984) Floral biology and fruit set in mango (Mangifera indica L.) cultivars 'Carabao', 'Pico' and 'KanchaMitha'. Philosphy Journal of crop science 9:47-51.

Randhawa GS， Damodaran VK (1961) Studies on floral biology and sex ratio in mango var. Chaunsa, Dashehari \& Krishanbhog. Indian. Journal Horticulture 18: pp.51-64.

Rathore, C. S. (2005). Genetic characterization of mango (Mangifera indica L.) germplasm under north Indian conditions. Ph. D. Thesis submitted to Post Graduate School, Indian Agricultural Research Institute, New Delhi, p-38-47

Sharma DK, Singh RN (1972) Investigation of self-incompatibility in (Mangifera indica L.). Acta Horticulturae 24: 126130.

Singh RN (1954) Studies on floral biology and subsequent developments of fruit in the mango varieties, Dashehari and Langra. Indian Journal Horticulture 
11:69-88.

Singh, L B (1960) The Mango-Botany, Cultivation and Utilization. Leonard Hill, London. International Journal of Recent Scientific Research pp. 93439346.

Spencer JL, Kennard WC (1955) Studies on Mango fruit set in Puerto Rico. Tropical Agriculture 32:323-330.

Thimmappaiah, Suman CL (1987) Sex in relation to fruit-set and fruit yield in mango. Punjab Horticulture 27(1-2):811.
Uthaiah BC, Indiresh KM, Rao ISA, Hannummaiah N (1988) Flower and sex variation in mango varieties under coastal Karnataka. Progressive Horticulture 20:120-122

Wagle PV (1929) A preliminary study of the pollination of the Alphonso mango. Agriculture Journal of India 24: 259263.

Yadav IS, Singh R (1993). Genetics resource of Mangifera, In: Advances in Horticulture, Malholtra publishing Housing, New Dehli, 1: 77-82.

\section{How to cite this article:}

Sunil Kumar Mandal, Kumari Karuna, Ashwini Kumar, Abhay Mankar and Sanjay Sahay. 2020. Floral Biology and Pollen Viability of Some Mango (Mangifera indica L.) Cultivars. Int.J.Curr.Microbiol.App.Sci. 9(06): 2390-2400. doi: https://doi.org/10.20546/ijcmas.2020.906.293 